\title{
Study of Nutrient Foramen in Humerus
}

\author{
Chandan Sintakala, ${ }^{1}$ Prabina Manandhar ${ }^{1}$ \\ 'Department of Anatomy, Lumbini Medical College, Palpa, Nepal.
}

\begin{abstract}
Introduction

Nutrient foramen is the natural opening present in the middle of the shaft of humerus. It passes the nutrient artery to the medullary cavity. Nutrient artery is the chief artery which enters into the bone through a nutrient foramen to provide nutrition its growth. It plays important role in healing during fracture, trauma and also important for bone grafting.

The objective of study was to identify the number of nutrient foramen in dry humerus and to observe direction and allocation of the nutrient foramina.
\end{abstract}

\section{Methods}

The study was performed in 200 (74 and 126 left) dry humeri. The samples were collected from medical and dental colleges of Nepal in years ranging from August 2018 to January 2020. The length of dry humerus were measured by vernier caliper, needle was used for direction of nutrient foramen.

\section{Results}

Out of 200 dry humeri, 143(71.5\%) had a single nutrient foramen, 44(22.0\%) had double, 9(4.5\%) had triple and $4(2.0 \%)$ had no nutrient foramen. The majority of nutrient foramen was observed in Anteromedial (91.5\%), 5.4\% in anterolateral and 1.5\% in posterior surface of humerus. The foraminal index $1(0.5 \%)$ bone recorded under Zone I, 182(91\%) in zone II and $13(6.5 \%)$ in zone III. The average foraminal index of bone was 56.18 and the average length of Humerus was $27 \mathrm{~cm}$.

\section{Conclusions}

The single nutrient foramen was predominant and majority of nutrient foramina were found in anteromedial surface.

Key words: humerus; nutrient foramen; foraminal index; nutrient artery; diaphysis.

\section{INTRODUCTION}

Humerus is a typical long bone of arm in human body extends from shoulder to elbow ${ }^{1}$. It is very important bone of upper limb with attachment of major muscles like biceps, triceps and deltoid etc. ${ }^{2}$ which transmits weight from hand, forearm to the axial skeleton through clavicle by the help of coracoclavicular, sternoclavicular ligaments. ${ }^{3}$

Correspondance: Chandan Sintakala, Department of Anatomy, Lumbini Medical College, Palpa, Tansen-11, Nepal. Email: csintakalachandan@gmail.com, Phone: +977-9849126574. 
Nutrient foramen is the small opening present in most of the bone of human body to transmit the nutrient artery which supply nutrition to different part of bone. Normally, nutrient foramen in humerus present near the mid-point of the anteromedial surface of its diaphysis along the medial border ${ }^{4,5}$ but different researches shows it is also presents in other surfaces anterolateral and posterior of humeral diaphysis. ${ }^{4}$ The nutrient artery divided into ascending and descending branch after it reached the medullary cavity of humerus. ${ }^{6}$ Each branch give off small helical branches which form the metaphyseal artery with hair pin loop ${ }^{7}$ has many clinical significance like trauma, orthopedic surgery, fracture repair and bone graft because it supply the metaphysis which is most important and actively growing part of bone. ${ }^{8}$

The study aimed to find out the numbers of nutrient foramen in dry humerus. The study showed the direction of foramina and their allocation according to foraminal index in Humerus. This type of study will aid in forensic department to identify the bone, surgery department for bone graft, medical student to understand the nutrient foramen of humerus with its direction and foraminal index.

\section{METHODS}

The study was carried out in 200 dry humeri (74 rights and 126 lefts) collected from medical and dental colleges of Nepal in years ranging from August 2018 to January 2020 AD.

Naturally extracted dry humeri were included in study but artificial, broken, damage humeri were not included in study.

\section{Procedure}

The nutrient foramen was observed in all surfaces; anteromedial, anterolateral and posterior surfaces and borders; medial, lateral and posterior of humeral diaphysis and noted in paper as it present either single, double or triple or more.

Then the direction of nutrient foramen was confirmed by inserting probe (as needle) inside the foramen. Foraminal index was calculated by the given formula i.e. foraminal index equals division of distance from proximal end of Humerus to the nutrient foramen by total length of Humerus and result multiply by $100.3,9$ The distances from proximal end of Humerus to the nutrient foramen and the total length of humerus were measured by using vernier caliper in $\mathrm{mm}$.

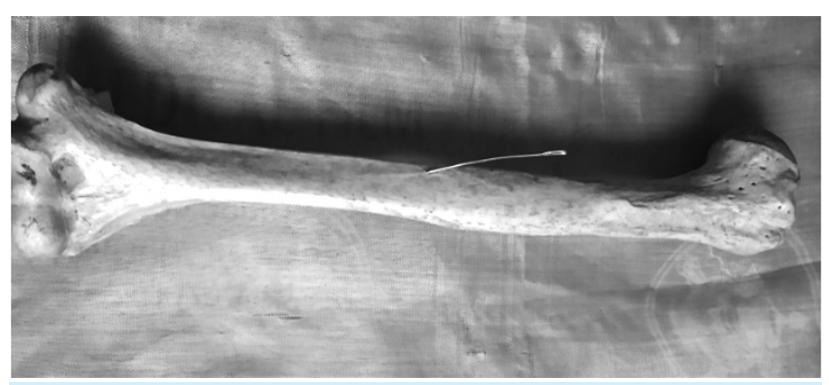

Figure 1. Showing the direction of nutrient foramen with the help of needle.

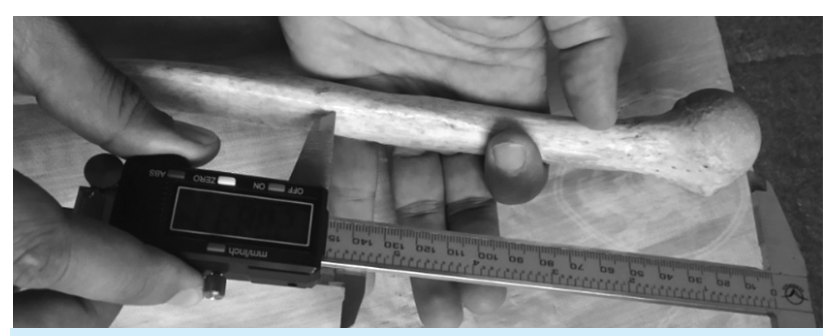

Figure 2. Showing the measurement of length of humerus from proximal end to the nutrient foramen.

Foraminal index is defined as the distance from proximal end of bone to nutrient foramen divided by total length of humerus which result multiply by 100 as follow. 3,9

\section{Foraminal index $=\frac{\begin{array}{c}\text { the distance from proximal end } \\ \text { of bone to nutrient foramen }\end{array}}{\text { Total length of humerus }} \times 100$}

According to foraminal index position of nutrient foramen in bone were classified into Zone I, Zone II, and Zone III. Zone I is defined as foramina index below 33.33, Zone II is defined as foraminal index from 33.33 to 66.66, similarly 
zone III is defined as the foraminal index above 66.66.

Thus the collected data were entered in Statistical Package for the Social Science (SPSS) 20 to calculate the frequencies and percentages of nutrient foramen, averages length of humerus and foraminal index, and P-value.

\section{RESULTS}

The present study showed 258 nutrient foramina in 200 humeri. The single nutrient foramen was present in $71.5 \%$ of humeri $(87.8 \%$ on right and $61.9 \%$ on left), double nutrient foramina in $22 \%$ of humeri $(6.8 \%$ on right and $31 \%$ on left), triple nutrient foramina in $4.5 \%$ of humeri (5.4\% on right and $4 \%$ on left) and nutrient foramen was absent in $2 \%$ of humeri. Majority of the nutrient foramina (91.5\%) were found to be present on the antero-medial surfaces of the shaft of humeri, $5 \%$ of the nutrient foramina were concentrated on the anterolateral surface and $1.5 \%$ of the nutrient foramina) were located on the posterior surface of the shaft of humeri. The mean foraminal index was 56.18. On the basis of zone, $91 \%$ were present in the middle one-third or Zone II of the shaft of humeri, $6.5 \%$ were present in Zone III and $0.5 \%$ of nutrient foramina were found to be present in Zone I of the shaft of humeri.

The results are shown in following tables.

Table 1. The frequency and percentage distribution of nutrient foramen in humerus.

\begin{tabular}{|c|c|c|c|c|}
\hline \multirow{2}{*}{$\begin{array}{c}\text { Nutrient } \\
\text { foramen }\end{array}$} & \multicolumn{2}{|c|}{ Right } & \multicolumn{2}{c|}{ Left } \\
\cline { 2 - 5 } & Frequency & Percent & Frequency & Percent \\
\hline Absence & - & - & 4 & 3.2 \\
\hline Single & 65 & 87.8 & 78 & 61.9 \\
\hline Double & 5 & 6.8 & 39 & 31.0 \\
\hline Triple & 4 & 5.4 & 5 & 4.0 \\
\hline Total & 74 & 100.0 & 126 & 100 \\
\hline
\end{tabular}

Table 2. The frequency and percentage distribution of nutrient foramen on surfaces of humerus.

\begin{tabular}{|l|l|l|l|l|}
\hline \multirow{2}{*}{ Surfaces } & \multicolumn{2}{c|}{ Right } & \multicolumn{2}{c|}{ Left } \\
\cline { 2 - 5 } & Frequency & Percentage & Frequency & Percentage \\
\hline $\begin{array}{l}\text { Absent } \\
\text { foramen }\end{array}$ & - & - & 4 & 3.2 \\
\hline Anteromedial & 68 & 91.8 & 115 & 91.2 \\
\hline Anterolateral & 5 & 6.8 & 5 & 4 \\
\hline Posterior & 1 & 1.4 & 2 & 1.6 \\
\hline Total & 74 & 100.0 & 126 & 100 \\
\hline
\end{tabular}

Table 3. The frequency and percentage distribution of nutrient foramen on the basis of Zone I, II, and III.

\begin{tabular}{|l|l|l|l|l|}
\hline \multirow{2}{*}{ Zone } & \multicolumn{2}{|c|}{ Right } & \multicolumn{2}{c|}{ Left } \\
\cline { 2 - 5 } & Frequency & Percentage & Frequency & Percentage \\
\hline $\begin{array}{l}\text { Absence } \\
\text { foramen }\end{array}$ & - & - & 4 & 3.2 \\
\hline I & 1 & 1.4 & - & - \\
\hline II & 68 & 91.9 & 114 & 90.5 \\
\hline III & 5 & 6.8 & 8 & 6.3 \\
\hline Total & 74 & 100.0 & 126 & 100 \\
\hline
\end{tabular}

\section{DISCUSSION}

The recent study was performed to determine the number of nutrient foramen in Humerus. In the present study the single nutrient foramen were present in $71.5 \%$ of humeri which was contrast to Yaseen et al. ${ }^{10}$ (88.5\%), Khan et al. ${ }^{11}(90.67 \%)$, and almost similar to Chandrasekaran et al. ${ }^{12}(76.74 \%)$, Anusha et al. ${ }^{13}(72 \%)$, Parmar et al. ${ }^{14}(72 \%)$, Muralimanju et al. (93.8), ${ }^{15}$ Kizilkananta et al. ${ }^{16}(68.32 \%)$, Carrol et al. $^{17}(67.61 \%)$. The nutrient foramen were located predominantly on antero-medial surface depicted by the study of Mansur et al. ${ }^{3}(88.86 \%)$, Chandrashekharan et al. (89.92\%) supported $91.5 \%$ of present study and different from Solanke et al. ${ }^{18}$ reported only $67 \%$. The prevalence of double nutrient foramen was found to be $22 \%$ and triple nutrient foramen was $4.5 \%$ in the recent study. Similar findings were present in the study investigated by Chandrasekaran et al. 
(20.54\% and 2.71\%), Parmar et al. (21.67\% and $3.33 \%$ ). About $2 \%$ of humerus didn't show the presence of nutrient foramen which corresponds to the study performed by Mansur et al. (1.98\%) and Kizilkananta et al.(1.98\%). The present study also reported that the mean foraminal index was $56.18 \%$ with the similar findings by Ukoha et al. ${ }^{19}(56.28 \%)$, Pereira et al..$^{20}(55.2 \%)$. The nutrient foramina were mainly situated in the middle $1 / 3^{\text {rd }}$ or zone II of the humerus $(91 \%)$.

Studies conducted by Mansur et al. (94.84\%), Solanke et al. ${ }^{18}(90 \%)$, Yaseen et al.(89\%) also showed the higher incidence of position of nutrient foramen in Zone II. However there is less incidence of nutrient foramen present in Zone I $(0.5 \%)$ with the similar result conducted

\begin{tabular}{|c|c|c|c|c|c|c|c|}
\hline Author & $\begin{array}{c}\text { Year } \\
\text { in } A D\end{array}$ & $\begin{array}{c}\text { Sample } \\
\text { size }\end{array}$ & $\begin{array}{c}\text { Single } \\
\%\end{array}$ & $\begin{array}{c}\text { Double } \\
\%\end{array}$ & Triple $\%$ & Four $\%$ & $\begin{array}{c}\text { Absence } \\
\%\end{array}$ \\
\hline Present study & 2020 & 200 & 71.5 & 22 & 4.5 & - & 2 \\
\hline Mansur et al. ${ }^{3}$ & 2016 & 253 & 60.87 & 28.85 & 6.32 & 1.98 & 1.98 \\
\hline Khan et al. ${ }^{11}$ & 2014 & 75 & 90.67 & 9.33 & - & - & - \\
\hline Chandrasekaran et al. ${ }^{12}$ & 2013 & 258 & 76.74 & 20.54 & 2.71 & - & - \\
\hline Anusha et al. ${ }^{13}$ & 2013 & 50 & 72 & 24 & - & - & 4 \\
\hline Parmar et al. ${ }^{14}$ & 2011 & 60 & 75 & 21.67 & 3.33 & - & - \\
\hline Muralimanju et al. ${ }^{15}$ & 2011 & 243 & 93.8 & 3.1 & - & - & 3.1 \\
\hline Kizilkananta et al. ${ }^{16}$ & 2007 & 101 & 68.32 & 21.78 & 6.93 & 0.99 & 1.98 \\
\hline Yaseen et al. ${ }^{10}$ & 2014 & 100 & 79 & 19 & 2 & - & - \\
\hline Forriol et al. ${ }^{5}$ & 1987 & 36 & 75 & 25 & - & - & - \\
\hline Carroll et al. ${ }^{17}$ & 1963 & 71 & 67.61 & 28.16 & 4.23 & - & - \\
\hline
\end{tabular}

\begin{tabular}{|l|l|l|l|l|l|}
\hline \multicolumn{6}{|c|}{ Table 5. Shows percentage of nutrient foramen present in different surface by various studies. } \\
\hline \multicolumn{1}{|c|}{ Author } & \multicolumn{1}{|c|}{ Year in AD } & Sample size & \multicolumn{1}{|c|}{ AM } & \multicolumn{1}{c|}{ AL } & \multicolumn{1}{c|}{ Posterior } \\
\hline Present study & $\mathbf{2 0 2 0}$ & $\mathbf{2 0 0}$ & $\mathbf{9 1 . 5}$ & $\mathbf{5}$ & $\mathbf{1 . 5}$ \\
\hline Mansur et al. & 2016 & 253 & 88.86 & 6.52 & 4.62 \\
\hline Solanke et al. ${ }^{18}$ & 2014 & 100 & 67 & 32 & 1 \\
\hline Yaseen et al. & 2014 & 100 & 88.5 & 3.5 & 8 \\
\hline Chandrashekharan et al. & 2013 & 358 & 89.92 & 1.55 & 8.53 \\
\hline
\end{tabular}

Note: AM: Anteromedial, AL: Anterolateral

\begin{tabular}{|c|c|c|c|c|c|}
\hline \multicolumn{7}{|c|}{ Table 6. Distribution of nutrient foramen according to foraminal index. } \\
\hline Author & Year in AD & Sample size & Zone I \% & Zone II \% & Zone III \% \\
\hline Present study & 2020 & 200 & 0.5 & 91 & 6.5 \\
\hline
\end{tabular}




\begin{tabular}{|l|c|c|c|c|c|}
\hline Mansur et al. & 2016 & 253 & 0.54 & 94.84 & 4.62 \\
\hline Solanke et al. & 2014 & 100 & 4 & 90 & 6 \\
\hline Yaseen et al. & 2014 & 100 & - & 89 & 11 \\
\hline Chandrashekharan et al. & 2013 & 358 & - & 86.43 & 13.57 \\
\hline
\end{tabular}

\begin{tabular}{|l|c|c|c|}
\hline \multicolumn{1}{|c|}{ Table 7. Mean foraminal index in different studies. } \\
\hline Author & Year in AD & Sample size & Foraminal index \\
\hline Present study & $\mathbf{2 0 2 0}$ & $\mathbf{2 0 0}$ & $\mathbf{5 6 . 1 8}$ \\
\hline Mansur et al. & 2016 & 253 & 55.20 \\
\hline Solanke et al. & 2014 & 100 & 52.65 \\
\hline Ukoha et al. ${ }^{19}$ & 2013 & 150 & 56.28 \\
\hline Pereira et al. & 2011 & 174 & 55.2 \\
\hline
\end{tabular}

\begin{tabular}{|l|c|c|c|c|c|c|}
\hline \multicolumn{7}{|c|}{ Table 8. Discuss on direction of nutrient foramen in percentage. } \\
\hline \multicolumn{1}{|c|}{ Author } & Year in AD & Sample size & NF & DD & DP & DH \\
\hline Present study & $\mathbf{2 0 2 0}$ & $\mathbf{2 0 0}$ & $\mathbf{2 5 8}$ & $\mathbf{9 8 . 4 7}$ & - & $\mathbf{1 . 5 3}$ \\
\hline Mansur et al. & 2016 & 253 & 736 & 100 & - & - \\
\hline Yaseen et al. & 2014 & 100 & 139 & 99.2 & - & 0.8 \\
\hline Kumar et al. & 2012 & 23 & 233 & 99.54 & - & 0.46 \\
\hline Khan et al. & 2014 & 75 & 109 & 97.06 & 2.94 & - \\
\hline
\end{tabular}

Note: NF: Number of nutrient foramen, DD: Directed to distal end of Humerus, DP: Directed to proximal end of Humerus, DH: Directed horizontally

by Mansur et al.(0.54\%). The nutrient foramen directed downwards recorded was $98.47 \%$ and $1.53 \%$ of nutrient foramen were directed horizontally. A study conducted by Yaseen et al. showed similar finding that $99.2 \%$ foramina were directed downward and $0.8 \%$ foramina were directed horizontally, Kumar S. et al. ${ }^{21}$ reported 99.54\% directed downward and $0.46 \%$ directed horizontally. There was only difference of about $1 \%$ in both foramina directed downward and horizontally.

In the study of Ara et al. ${ }^{22} \mathrm{p}$-value is not significant at $p=0.319$ in presence, absence, number, location and position of nutrient foramen in male and female left dry humeri. The present study showed p-value as 0.05 which showed that significant among presence, absence, number, location and position of nutrient foramen did exist. The study by Bokariya et al. ${ }^{23}$ showed not significant at $\mathrm{p}>0.05$ which was difference from Ara et al and present study. The overall discussion was shown in table 4-6 from different researcher.

Nutrient artery enters through nutrient foramen present in bone and the damage to nutrient artery may lead to delayed union following fracture of shaft of humerus. ${ }^{11}$ The knowledge about the position of nutrient foramen will be helpful for 
orthopedic surgeon to minimize the damage to nutrient artery during surgical procedures.

\section{CONCLUSIONS}

The study showed more numbers of single nutrient foramina present in anteromedial surface of Humerus directed downward. Most of the nutrient foramina located on the Zone II according to the foraminal index.

These type of study will help in surgical procedure of fracture, trauma and will give knowledge about variation of nutrient foramen present, so that operator may not confused during operation.

\section{REFERENCES}

1. Datta AK. General Anatomy: General Consideration. $4^{\text {th }}$ edition. Kolkata. Current Books International 1997:75-77.

2. Standring S, Peter L. Williams, Williams Warwick, Dyson Bannister. Gray's Textbook of Anatomy: Pectoral girdle, Axilla. $37^{\text {th }}$ edition. Elseveir Churchil Livingstone, London 1993:299-300 and 759.

3. Mansur DI, Manandhar P, Haque MK, Mehta DK, Duwal S, Timalsina B. A Study on Variations of Nutrient Foramen of Humerus with its Clinical Implications. Kathmandu University Med J. 2016;14(53):78-83

4. Poudel A. Satyal B. A Study of Variation of Nutrient Foramen of Dry Adult Humerus. J Nepalgunj Med Coll, 2019:17(1);38-42

5. Forriol FC, Gomez LP, Gianonatti MA, Fernandez RV. A study of the nutrient foramina in human long bones. Surg Radiol Anat. 1987;9:251-5

6. Shulman SS. Observations on the nutrient foramina of the human radius and ulna. Anat Rec. 1959;134:685-97

7. Mysorekar VR. Diaphysial nutrient foramina in human long bones. J Anat. 1967;10(1):813-22.

8. Patake SM, Mysorekar VR. Diaphysial nutrient foramina in human metacarpals and metatarsals. J Anat. 1977;124(2):299304.

9. Lewis OJ. The blood supply of developing long bones with special reference to the metaphyses. J Bone Joint Surg. 1956;38:928933.

10. Yaseen S, Nitya W, Ravinder $M$. Morphological and topographical study of nutrient foramina in adult humerii. Int J Innov Res Sci Eng Technol. 2014;3(4):7-10.

11. Khan AS, Shah Z, Inayat Q. Anatomical variations in diaphyseal nutrient foramina of humerus in cadavers from khyber pakhtunkhwa, pakistan. Khyber Med Univ J. 2014; 6(1):18-21.

12. Chandrasekaran S, Shanthi KC. A study on the nutrient foramina of adult humerii. J Clin Diagn Res. 2013;7(6):975-7.

13. Anusha P, Naidu MP. A study on the nutrient foramina of long bones. Jour of Med Sci and Tech. 2013;2(3):150-7.

14. Parmar AMB, Vaghela B, Shah K, Patel B, Tridevi B. Morphometric analysis of nutrient foramina in human typical long bones of upper limb.Natl J Integr Res Med. 2014;5(5): 26-9.

15. Murlimanju BV, Prashanth KU, Prabhu LV, Saralaya VV, Pai MM, Rai R. Morphological and topographical anatomy of nutrient foramina in human 
upper limb long bones and their surgical importance. Rom J Morphol Embryol. 2011;52(3):859-62.

16. Kizilkanata E, Boyana N, Ozsahina ET, Soamesb R, Oguza O. Location, number and clinical significance of nutrient foramina in human long bones. Ann Anat. 2011;18(9):87 - 95.

17. Carroll SE. A study of the nutrient foramina of the humeral diaphysis. $J$ Bone Joint Surg. 1963;45:176 -81

18. Solanke KS, Bhatnagar R, Pokhrel R. The number and position of nutrient foramina in humerus, radius, ulna of human dry bones of indian origin with clinical correlation. OA Anatomy. 2014;2(1):1-8.

19. Ukoha UU, Umeasalugo KE, Nzeako HC, Ezejindu DN, Ejimofor OC, Obazie IF. A study of nutrient foramina in long bones of nigerians. Natl J Med. 2013;3(4):304- 8.
20. Pereira GAM, Lopes PTC, Santos AMPV, Silveira FHS. Nutrient foramina in the upper and lower limb long bones: Morphometric study in bones of southern brazilian adults. Int J Morph. 2011;29(2):514-20

21. Kumar S, Kathiresan K, Gowda MST, Nagalaxmi. Study of diaphyseal nutrient foramina in human long bones. Anat Karnataka. 2012;6(2):66-70.

22. Ara JG, Naushaba H, Khan MH, Khan LF, Farhat N. Morphometric Study of Nutrient Foramen in Adult Human Dry Left Humerus. Mymensingh Med J. 2016 Jan;25(1):45-9

23. Bokariya P, Gudadhe D, Kothari R, Murkey PN, Shende MR. Comparison of humerus and femur with respect to location and number of nutrient foramina. Indian J Forens Med and Patho. 2012;5(2):79-81.

Citation: Sintakala C, Manandhar M. Study of Nutrient Foramen in Humerus. JCMS Nepal. 2020; 16(4):252-58. 